\title{
EVALUATION OF LIVER ENZYMES IN PREGNANCY WITH COMPLICATIONS
}

\section{Sreeman N Junagam ${ }^{1}$, Balu Jatthavath ${ }^{2}$.}

${ }^{1}$ Assistant Professor, Department of Biochemistry, Alluri Seetarama Raju Institute Of Medical Sciences, Eluru- West Godavari- Dt- India.

*2 Assistant Professor, Department of pharmacology, Alluri Seetarama Raju Institute Of Medical Sciences, Eluru- West Godavari- Dt- India.

\section{ABSTRACT}

Background: The hormones secreted to support foetal growth and development show effect on metabolic, synthetic and excretory function of liver in pregnancy. Complications of pregnancy added to this may aggravate and precipitate liver dysfunction. Liver dysfunction in pregnancy has serious consequences. So in this study we studied the liver function tests in normal pregnancy and complicated pregnancy, distribution of complications according to maternal age and the association of liver function to all complications of pregnancy.

Materials and Methodology: This observational cross sectional study was conducted in Alluri Seetarama Raju Institute of Medical Sciences from March 2007 to September 2007 involving 46 normal pregnant women (control Group) and 40 complicated pregnant women (study Group).

Results: We found more complications in the pregnancy with increasing maternal age i.e., after 30 years (60\%), and Hyperemesis gravidarum (20\%) and urinary tract infection $(20 \%)$ are the most common complications found in study group. We found significantly elevated levels of SGPT (ALT) study group when compared to control group ( $\mathrm{P}=0.001)$.

Conclusion: Elderly maternal age will result in more complications which can lead to still births and maternal mortality. Complications of pregnancy can lead to liver dysfunction which may be sometimes difficult to find out because of lack of established reference range for LFT.

KEY WORDS: Normal pregnancy, complicated pregnancy, liver function tests (LFT).

Address for correspondence: Dr. Balu Jatthavath, Assistant Professor, Department of pharmacology, Alluri Seetarama Raju Institute Of Medical Sciences, Eluru- West Godavari-Dt- India.

E-Mail: drjatthavath@gmail.com

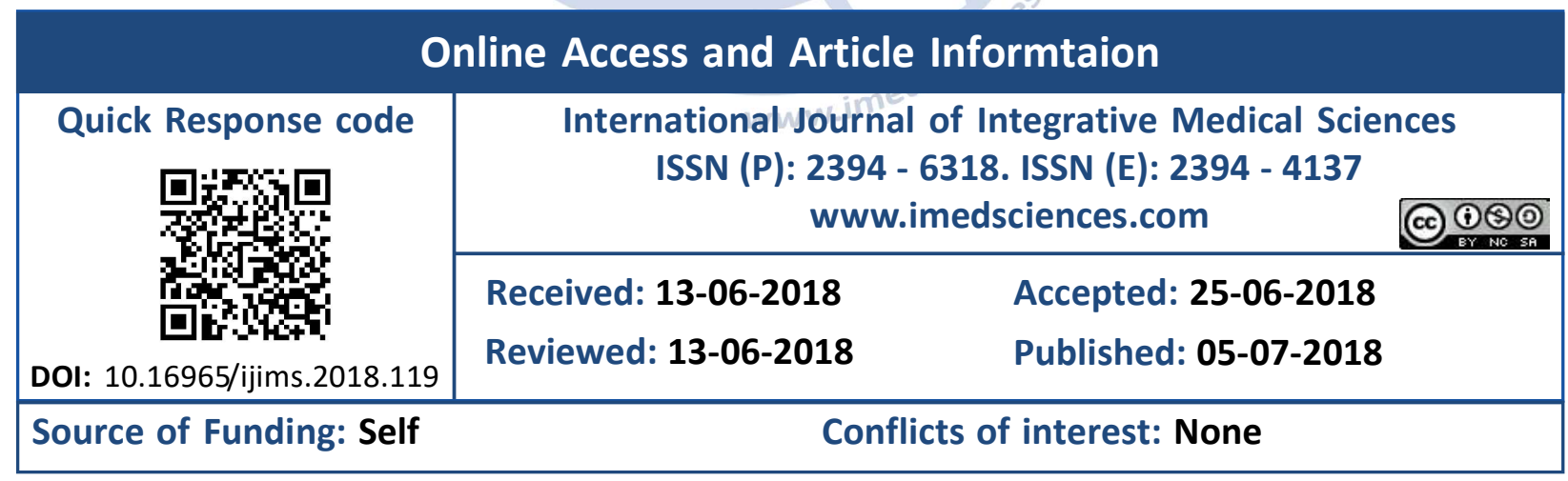

\section{BACKGROUND}

Three percent of pregnant women are cause of liver dysfunction in pregnancy. When severe, they are associated with significant morbidity and mortality for both mother and infant [1]. A rapid evaluation to distinguish them from non-pregnancy related liver dysfunction is essential, in order to facilitate appropriate management. Liver disease unrelated to pregnancy can present de novo in pregnancy, or pregnancy can occur in women with preexisting liver pathology. Several physiologic changes occur dur-ing pregnancy and could pose difficulty in evaluating hepatobiliary function because they may be misinterpreted as pathological. The blood volume expands during pregnancy due to retention of salt and water. This induces a state of hemodilution, an increase in cardiac output, and a reduction in systemic vascular resistance and systemic blood pressure. These changes peak during the second trimester then plateau until delivery. Consequently 
serum levels of uric acid, albumin, total protein and hematocrit are decreased. On the other hand, serum alkaline phosphatase levels may be el-evated three to four folds due to placental production while serum values of as-partate aminotransferase (AST), alanine aminotransferase (ALT), gamma-gluta-myl transpeptidase (GGT), bilirubin and prothrombin time remain in the normal range or decreased $[2,3]$.

Female sex hormones affect the hepatobiliary system in several ways some of which could include intra-hepatic cholestasis, tumour formation (adenoma) and growth of haemangioma, gallbladder disease and hepatic vein thrombosis. The size of the liver is generally unchanged during normal pregnancy and liver histology remains essen-tially normal throughout gestation [3]. Causes of abnormal liver function tests specific to pregnancy include intrahepatic cholestasis of pregnancy, preeclampsia, haemolysis-elevated liver enzymeslow platelets (HELLP) and rarely acute fatty liver of pregnancy. All of these can cause significant fetal and maternal morbidity and mortality [2]. The liver is not primarily involved in pre-eclampsia and eclampsia, but severe cases may be associated with liver dysfunction. Histology of the liver in these cases showed periportal haemorrhage and fibrin deposition without an inflammatory reaction, similar to the picture seen in disseminated intravascular coagulation, which is not uniform [4]. Liver involvement is seen in about $50 \%-60 \%$ of patients with Hyperemesis gravidarum [5]. Most commonly seen are mild serum aminotransferase elevations, but there are reported cases of severe transaminase elevations (alanine aminotransferase (ALT) levels 400 to over $1000 \mathrm{U} / \mathrm{L}$ ) [6]. Mild hyperbilirubinemia with mild jaundice can be seen as well. So we studied the liver function tests in normal pregnancy and pregnancy with complications.

\section{MATERIALS AND METHODOLOGY}

This observational cross sectional study was conducted in Alluri Seetarama Raju Institute of Medical Sciences from March 2007 to September 2007. All pregnancy women were selected randomly (unsystematic randomization). 46 Control Group (Normal Pregnant women), and 40 Study Group (Pregnancy with complications women (UTI, ANEMIA, POLYHYDROMNIAS, APH, PREECCLAMPSIA, GESTATIONAL DIABETES, PLACENTA PREVIA, HYPEREMESIS GRAVIDARUM )) both were interviewed by authors and case details collected both from OPD and admitted patients. Detailed history was taken. Blood samples collected at the same time and sent to the laboratory. LFT were done in central laboratory of Alluri Seetarama Raju Institute of Medical Sciences by standard procedures. Statistical analysis was done by proportions and independent's' test by using PASW 18.0 (predictive analytical soft ware). $P$ value $<0.05$ is considered as statistically significant.

\section{RESULTS}

Table 1: Age distribution in normal and complicated pregnancy.

\begin{tabular}{|c|c|c|}
\hline Age & $\begin{array}{c}\text { Normal } \\
\text { pregnancy }\end{array}$ & $\begin{array}{c}\text { Complicated } \\
\text { pregnancy }\end{array}$ \\
\hline $12-18$ & $2(4.34 \%)$ & $1(2.5 \%)$ \\
\hline $19-24$ & $16(34.78 \%)$ & $4(10 \%)$ \\
\hline $25-30$ & $13(28.2 \%)$ & $11(27.5 \%)$ \\
\hline $31-36$ & $12(26 \%)$ & $12(30 \%)$ \\
\hline$>36$ & $3(6.5 \%)$ & $12(30 \%)$ \\
\hline TOTAL & 46 & 40 \\
\hline
\end{tabular}

Inference: Incidence of complication is more after 30 years of age (60\%).

Table 2: Distribution of complications of pregnancy.

\begin{tabular}{|c|c|c|}
\hline Complication & NO & Percentage \\
\hline UTI & 8 & $20 \%$ \\
\hline ANEMIA & 6 & $15 \%$ \\
\hline POLYHYDROMNIAS & 2 & $5 \%$ \\
\hline APH & 3 & $7.50 \%$ \\
\hline PREECLAMPSIA & 4 & $10 \%$ \\
\hline GESTATIONAL DIABETES & 4 & $10 \%$ \\
\hline PLACENTA PREVIA & 5 & $12.50 \%$ \\
\hline HYPEREMESIS GRAVIDARUM & 8 & $20 \%$ \\
\hline TOTAL & 40 & $100 \%$ \\
\hline
\end{tabular}

Inference: Hyperemesis gravidarum and UTI (20\%) are most common complications.

Table 3: MEAN \pm SD values of parameters in normal and complicated pregnancy.

\begin{tabular}{|c|c|c|}
\hline Parameter & $\begin{array}{c}\text { Normal Pregnancy } \\
(\mathrm{n}=\mathbf{4 6})\end{array}$ & $\begin{array}{c}\text { Complicated } \\
\text { pregnancy }(\mathrm{n}=\mathbf{4 0})\end{array}$ \\
\hline $\begin{array}{c}\text { HEMOGLOBIN } \\
\text { (gm/dl) }\end{array}$ & $11.45 \pm 1.836$ & $11.38 \pm 1.26$ \\
\hline $\begin{array}{c}\text { SERUM BILIRUBIN } \\
(\mathrm{mg} / \mathrm{d} \text { l) }\end{array}$ & $0.376 \pm 0.306$ & $0.3 \pm 0.169$ \\
\hline AST (U/I) & $18.23 \pm 8.63$ & $18.7 \pm 9.17$ \\
\hline ALT (U/I) & $16.63 \pm 9.89$ & $23.77 \pm 9.07$ \\
\hline ALP (U/I) & $133.97 \pm 74.02$ & $134.87 \pm 54.68$ \\
\hline $\begin{array}{c}\text { TOTAL PROTEIN } \\
\text { (gm/l) }\end{array}$ & $5.71 \pm 2.47$ & $6.02 \pm 2.52$ \\
\hline
\end{tabular}

Inference: SGPT values are more in complicated 
pregnancy in comparison with normal pregnancy.

Table 4: Showing ' $t$ ' value and ' $p$ ' value of normal pregnancy vs complicated pregnancy.

\begin{tabular}{|c|c|c|c|}
\hline Parameter & $\begin{array}{c}\text { Degree of } \\
\text { freedom } \\
\left(\mathbf{n}_{1}+\mathbf{n}_{\mathbf{2}}-\mathbf{2}\right)\end{array}$ & 't' value & P-value \\
\hline HEMOGLOBIN & 84 & 0.2 & 0.842 (NS) \\
\hline $\begin{array}{c}\text { SERUM TOTAL } \\
\text { BILIRUBIN }\end{array}$ & 84 & 1.394 & 0.167 (NS) \\
\hline AST & 84 & 0.24 & $0.811(\mathrm{NS})$ \\
\hline ALT & 84 & 3.469 & $0.001(\mathrm{~S})$ \\
\hline ALP & 84 & 0.063 & $0.950(\mathrm{NS})$ \\
\hline TP & 84 & 0.569 & $0.571(\mathrm{NS})$ \\
\hline
\end{tabular}

Inference: Significant increase observed in SGPT of complicated pregnancy against normal pregnancy.

\section{DISCUSSION}

There is increasing trend of complications after the age of 30 years in our study. $60 \%$ (24 out of 40) of total complicated pregnancies are occurring after 30 years of age (table 3 ). Similar findings were observed in the studies conducted by Barbara Luke et.al. [7] and Ling Huang et.al. [8]. It may be due to the fact that older maternal age may be associated with an increase in obstetric complications secondary to a higher incidence of underlying medical disease, decreased cardiovascular reserve, and diminished ability to adapt to physical stress that may accompany aging [7].

In our study we found hyperemesis gravidarum and UTI as the most common complications among all other (Table 2). This finding is consistent with the study conducted by Harish K et.al. [9]. Many other studies show pre eclampsia, haemorrhage, and infection during pregnancy as most common cause of maternal mortality [10]. These complications causing maternal mortality are less in our study. Instead, hyperemesis gravidarum and UTI are more which do not cause maternal mortality.

All markers of liver function are generally reduced or low during pregnancy due to the expansion of extracellular fluid. Hence serum albumin, transaminases (AST and ALT) and total bilirubin are low compared with the non-pregnant state. The only exception is serum alkaline phosphatase (ALP) which is elevated due to ALP of placental origin [2]. The sex steroids show effect and cause a decrease in all phases of liver function, uptake, transformation, and excretion in complicated pregnancy [11]. Subclinical hepatic damage is known to occur in $\mathrm{PIH}$ and eclampsia and this is reflected by elevated liver enzymes [12]. Liver involvement is seen in about $50 \%-60 \%$ of patients with Hyperemesis gravidarum (6). Most commonly seen are mild serum aminotransferase elevations and mild hyperbilirubinemia with mild jaundice [7]. In pre eclampsia, another frequent complication of pregnancy, liver is involved and aminotransferases are increased mainly due to vasoconstriction of hepatic vasculature [13].

In our present study the findings are consistent with the general conception and all the values observed are within the range in normal pregnancy. In complicated pregnancy ALT values are increased when compared to normal pregnancy (Table 3 and 4) which is statistically significant also ( $P$ value 0.001 ). This finding is consistent with other studies $[4-6,9,14,15)$.

Harish K et.al., Showed that Hyperemesis gravidarum and viral hepatitis were the most common causes of abnormal LFT [9]. As Hyperemesis gravidarum is the most frequent complication found in our study, which may have resulted in elevated ALT in complicated pregnancy when compared to normal pregnancy [6]. The study conducted by Raman L, et.al., indicated that both SGPT (ALT) and SGOT (AST) though within the upper limit of the normal range, were significantly elevated in severe $\mathrm{PIH}$ and in eclampsia as compared to the controls [14]. But in our study SGOT (AST) levels are almost same in normal and complicated pregnancy, except SGPT (ALT) levels. Bernuau J mentioned that, it should be emphasized that serum AST or ALT activity values above the upper normal limit before labor should be considered pathologic and should lead to further investigations [16]. Eventhough the ALT levels at upper normal limit, there is significant increase in complicated pregnant group compared to normal pregnancy $(P=0.001)$ indicating the role of complications in liver dysfunction.

\section{CONCLUSION}

Our study indicates that there is normal liver 
function in normal pregnancy. Complications of pregnancy can lead to liver dysfunction which may be sometimes difficult to find out because of lack of established reference range for LFT. Elderly maternal age will result in more complications which can lead to still births and maternal mortality.

\section{REFERENCES}

[1]. Rachel H. Westbrook, Geoffrey Dusheiko, Catherine Williamson. Pregnancy and liver disease. Journal of Hepatology 2016;64:933-45.

[2]. Yannick Bacq, Olivier Zarka, Jean-Franc et.al. Liver Function Tests in Normal Pregnancy: A Prospective Study of 103 Pregnant Women and 103 Matched Controls, hepatology, 1996;23:1030-4.

[3]. Hacker N, Moore G, Gambone J. Essentials of obstetrics and gynaecology. Fourth edition. Philadelphia:Elsevier Saunders; 2004.

[4]. Steven M M, Progress report, Pregnancy and liver disease Gut, 1981; 22: 592-614.

[5]. Hepburn IS, Schade RR. Pregnancy-associated liver disorders. Dig Dis Sci. 2008;53:2334-58.

[6]. Conchillo JM, Pijnenborg JM, Peeters P, Stockbrugger RW, Fevery J, Koek GH. Liver enzyme elevation induced by hyperemesis gravidarum: aetiology, diagnosis and treatment. Neth J Med. 2002; 60:374-8.

[7]. Barbara Luke, Morton B. Brown, Contemporary Risks of Maternal Morbidity and Adverse Outcomes With Increasing Maternal Age and Plurality, Fertil Steril. 2007; 88(2): 283-93.

[8]. Ling Huang, Reg Sauve, Nicholas Birkett, Dean Fergusson,Carl van Walraven, Maternal age and risk of stillbirth: a systematic review, CMAJ. 2008; 178(2): 165-72.
[9]. Harish K, Nitha R, Harikumar R, Sunil Kumar K, Varghese T, Sreedevi NS, Bushrath K, Sandesh K, Tony J, Prospective evaluation of abnormal liver function tests in pregnancy. Trop Gastroenterol. 2005; 26(4):188-93.

[10]. Maternal mortality: estimates developed by WHO, Geneva, World Health Organization, 2008. Available from http://www.who.int/making_pregnancy_ safer/events $/ 2008 / \mathrm{mdg} 5 /$ factsheet_maternal_ mortality.pdf.

[11]. Van Thiel DH, Gavaler JS. Pregnancy-associated sex steroids and their effects on the liver. Semin Liver Dis 1987; 7:1-7.

[12]. Killam AP, Dillard SH, Patton RC, Pederson PR. Pregnancy induced hypertension complicated pregnancies. Am J Obstet Gynecol 1975; 123:823-8.

[13]. Knox TA, Olans LB. Liver disease in pregnancy. N Engl J Med. 1996; 335:569-76.

[14].Raman L, Pawashe AB, Yasodhara P. Hyperferritinemia in pregnancy induce hypertension and eclampsia. 1992; 38:65-7.

[15]. Girling J.C , ow E.D , Smith J.H, Liver function tests in pre-eclampsia:importance of comparison with a reference range derived for normal pregnancy Journal of Obstetrics and Gynaecology. 1997;104:246-50.

[16].Bernuau J. Complications hépatiques de la grossesse. Rev Prat. 2003; 53(17): 1889-93.

How to cite this article: Sreeman N Junagam, Balu Jatthavath. EVALUATION OF LIVER ENZYMES IN PREGNANCY WITH COMPLICATIONS. Int J Intg Med Sci 2018;5(6):659-662. DOI: 10.16965/ ijims.2018.119 